\title{
A child with a novel ACAN missense variant mimicking a septic arthritis
}

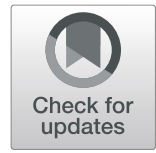

\author{
Angelo Florio ${ }^{1 \dagger}$, Riccardo Papa $^{1^{* \dagger}} \mathbb{D}$, Roberta Caorsi ${ }^{1}$, Alessandro Consolaro ${ }^{1}$, Roberto Gastaldi ${ }^{2}$, \\ Marco Gattorno ${ }^{1}$ and Paolo Picco ${ }^{1}$
}

\begin{abstract}
Heterozygous mutations of the ACAN gene have been associated with a broad spectrum of non-lethal skeletal dysplasias, called Aggrecanopathies. We report a case of a child with severe inflammatory elbow involvement mimicking septic arthritis who carried the new ACAN missense variant c.6970 T > C, p.Trp2324Arg. The comprehensive clinical evaluation of the patient and his family, focused on the associated clinical features (facial dysmorphisms, short stature, brachydactily), led us to suspect a hereditary condition. Our findings suggest that Aggrecanopathies should be considered in children with familial short stature, poor growth spurt and joint involvement.
\end{abstract}

Keywords: Pediatric rheumatology, Arthritis, Osteochondritis dissecans, ACAN, Aggrecanopathy

Sir,

Aggrecan is a chondroitin sulphated proteoglycan encoded by the $A C A N$ gene with essential structural functions in the extracellular matrix of cartilages [1]. Heterozygous ACAN mutations have been associated with a broad spectrum of non-lethal skeletal dysplasias, called Aggrecanopathies, including spondyloepimetaphyseal dysplasia, Kimberly type spondyloepiphyseal dysplasia, autosomal dominant short stature, early onset osteoarthritis and recurrent osteochondritis dissecans (OCD) [2-5].

Here, we present a child with severe inflammatory elbow involvement mimicking septic arthritis who carried a new missense variant of the $A C A N$ gene.

A 14-year-old boy developed swelling and pain at the right elbow after a physical effort. Symptoms were not associated to other systemic inflammatory signs and worsened during the following days, leading to a severe joint limitation. Laboratory tests and X-ray of the right elbow were normal. Non steroidal anti-inflammatory drugs (NSAIDs) were administered for a month without any improvement.

\footnotetext{
* Correspondence: grafomai@hotmail.it

${ }^{+}$Angelo Florio and Riccardo Papa contributed equally to this work.

${ }^{1}$ Pediatric Rheumatology Clinic, IRCCS Istituto Giannina Gaslini, Via Gerolamo

Gaslini 5, 16147 Genova, Italy

Full list of author information is available at the end of the article
}

The patient was admitted to our Institute after 2 months of symptoms onset. On physical examination, acute arthritis of the right elbow was present: it appeared painful and warm, without local erythema. Laboratory tests showed slight elevation of the acute phase reactants (C reactive protein $1.7 \mathrm{mg} / \mathrm{dl}$, erythrocyte sedimentation rate $26 \mathrm{~mm} / \mathrm{h}$ ). Ultrasound revealed a distension of coronoid and olecranon recess with thickening of the synovial membrane. Arthrocentesis was performed: culture tests and cell count of synovial fluid ruled out a septic arthritis. Elbow magnetic resonance imaging (MRI) revealed a bone fragment detachment from the humeral condyle (Fig. 1a) and diagnosis of OCD was made.

At physical examination, minor skeletal dysmorphisms were noted such as dolichocephaly, hypotelorism, arched palate and brachydactyly of the IV fingers. Moreover, the parents reported a previous episode of OCD at the right knee and pediatric endocrinological evaluations because of severe growth retardation (height always below -2 SDS).

Notably, when the patient was aging 8 years, short stature was documented (height $112 \mathrm{~cm},-2.4$ SDS): insulin tolerance test and L-arginin stimulation test disclosed blunted growth hormone $(\mathrm{GH})$ response (3.16 $\mathrm{ng} / \mathrm{ml}$ and $14.3 \mathrm{ng} / \mathrm{ml}$ maximum peak, respectively). Normal plasma concentration of insulin-like growth 

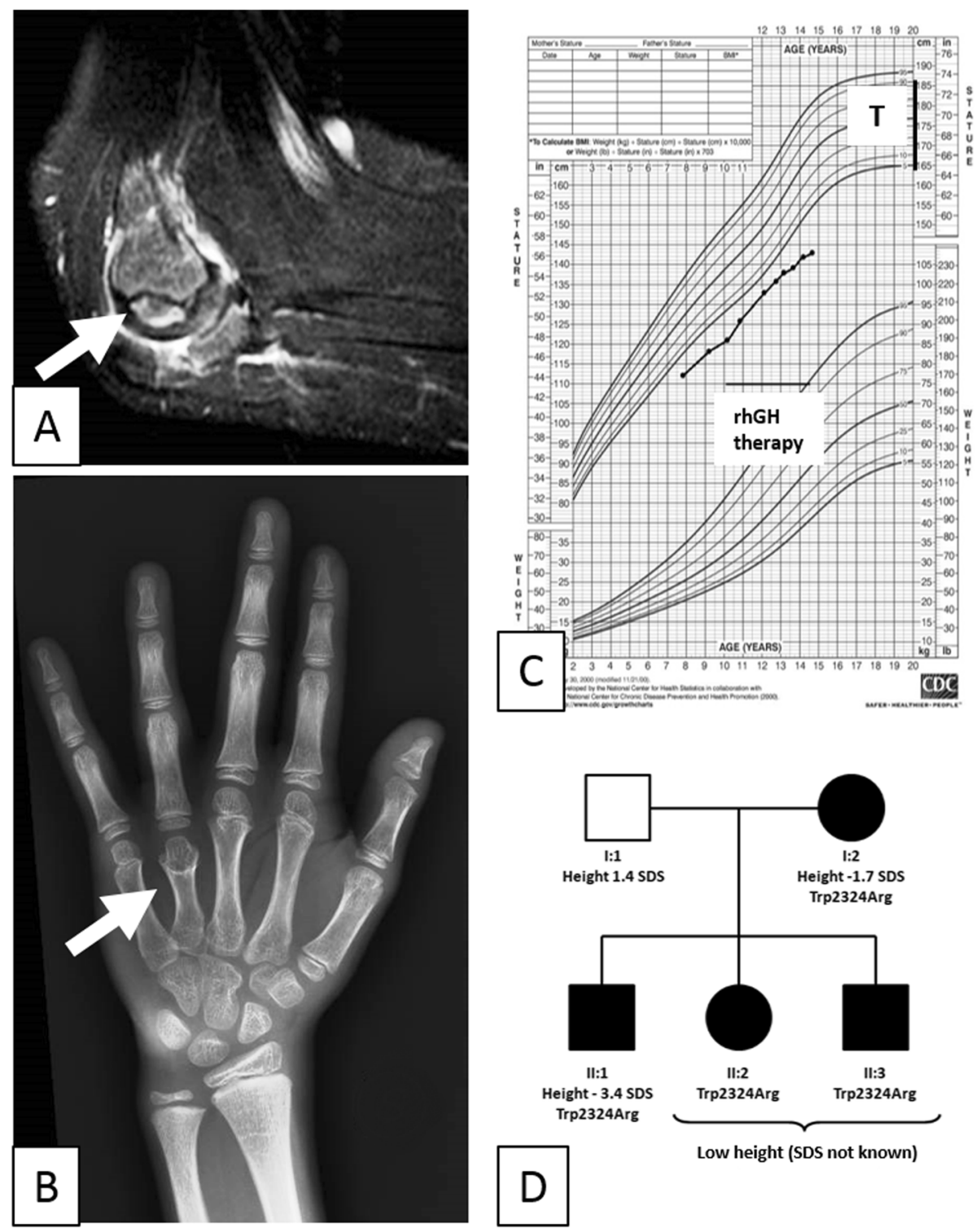

Fig. 1 Main features of our patient. Sagittal T2-weighted MRI of the right elbow shows joint distention, synovial thickening, and spongious edema of the humeral condyle with nidus (a, arrow tip). X-ray of the left hand shows bone age delay of 2 years with 4 th metacarpal bone brachydactyly (b, arrow tip). CDC growth chart of the patient ( $\mathbf{c}, T=$ target height). Family pedigree (d)

factor 1 was detected. Since growth retardation persisted, a further endocrinological evaluation was performed when he was 10 (height $121.4 \mathrm{~cm},-2.5 \mathrm{SDS}$ ). X-ray of the left hand revealed a bone age delay of 2 years according the Greulich and Pyle atlas, associated with brachydactyly of the 4th finger (Fig. 1b). Brain MRI showed a partially empty sella without anterior pituitary gland abnormalities. Since the insulin tolerance test showed a hypoglycemicinduced GH peak of $6.27 \mathrm{ng} / \mathrm{ml}$, the diagnosis of isolated GH deficit was pointed out and recombinant human GH (rhGH) treatment started. Nonetheless, poor growth spurt and impaired height velocity rate (-3.5 SDS) were documented despite the increasing dose of rhGH (Fig. 1c).
The patient was admitted to our Institute with a suspiction of septic arthritis; after the diagnosis of the elbow OCD, we critically re-evaluated the patient history. Namely, i) recurrent episodes of OCD, ii) short stature poorly responsive to the rhGH treatment, and iii) mild skeletal and facial dysmorphisms, led us to hypothesize a form of Aggrecanopathy.

Molecular analysis of the ACAN gene by Sanger sequencing revealed the novel missense variant c.6970 $\mathrm{T}>\mathrm{C}$, p.Trp2324Arg in the G3 domain of the protein. Intra-familial molecular analysis detected the same variant in the mother, who showed short stature (height $152 \mathrm{~cm},-1.7 \mathrm{SDS}$ ), and his two siblings who displayed 
short stature and brachydactyly, without history of OCD (Fig. 1d).

Since the c.7249G > A variant of the Aggrecan G3 domain has already been described in patients with OCD, short stature, and early-onset osteoarthritis [6], it seems reasonable to hypothesize that the ACAN missense variant can explain the overall clinical features of our patient and his family. Moreover, the atypical presentation of our patient highlights a possible role of this new $A C A N$ gene variant in joint involvement.

In conclusion, we report a case of Aggrecanopathy where an inflammatory process of the joint mimicking a septic arthritis was the most significant symptom. A comprehensive paediatric evaluation focused on his clinical features (facial dysmorphisms, short stature, and brachydactily) led us to the correct diagnosis and to find other affected family members. Our findings suggest that Aggrecanopathies should be considered in children with familial short stature, poor growth spurt and recurrent inflammatory joint involvement.

\section{Abbreviations}

GH: Growth hormone; OCD: Osteochondritis dissecans; rhGH: Recombinant human $\mathrm{GH}$

\section{Acknowledgements}

The authors would like to thank the patient and family for the consent to publish the data and Dr. Tuula Rinne to perform the molecular analysis.

\section{Authors' contributions}

$A F, R P, R C, A C$ drafted the manuscript. $R G, M G$, PP reviewed the manuscript All Authors approved the final version as submitted.

\section{Funding}

The authors declare that they have no funding for this study.

\section{Availability of data and materials}

The datasets used and/or analyzed during the current study are available from the corresponding author on reasonable request.

Ethics approval and consent to participate

Not applicable.

\section{Consent for publication}

The authors declare that they have obtained the consent for publication from the described patient and family.

\section{Competing interests}

The authors declare that they have no competing interests.

\section{Author details}

'Pediatric Rheumatology Clinic, IRCCS Istituto Giannina Gaslini, Via Gerolamo Gaslini 5, 16147 Genova, Italy. ${ }^{2}$ Pediatric Endocrinology Clinic, IRCCS Istituto

Giannina Gaslini, Genova, Italy.

Received: 3 June 2019 Accepted: 16 September 2019

Published online: 20 November 2019

\section{References}

1. Lauing $\mathrm{KL}$, Cortes M, Domowicz MS, et al. Aggrecan is required for growth plate cytoarchitecture and differentiation. Dev Biol. 2014;396:224-36.

2. Tompson SW, Merriman B, Funari VA, et al. A recessive skeletal dysplasia, SEMD aggrecan type, results from a missense mutation affecting the Ctypelectin domain of aggrecan. Am J Hum Genet. 2009;84:72-9.
3. Gleghorn L, Ramesar R, Beighton P, Wallis G. A mutation in the variable repeat region of the aggrecan gene (AGC1) causes a form of spondyloepiphyseal dysplasia associated with severe, premature osteoarthritis. Am J Hum Genet. 2005;77:484-90.

4. Stattin $\mathrm{EL}$, Wiklund $\mathrm{F}$, Lindblom $\mathrm{K}$, et al. A missense mutation in the aggrecan C-type lectin domain disrupts extracellular matrix interactions and causes dominant familial osteochondritis dissecans. Am J Hum Genet. 2010;86:126-37.

5. Nilsson O, Guo MH, Dunbar N, et al. Short stature, accelerated bonematuration, and early growth cessation due to heterozygous aggrecan mutations. J Clin Endocrinol Metab. 2014:99:E1510-8.

6. Gibson BG, Briggs MD. The Aggrecanopathies: an evolving phenotypic spectrum of human genetic skeletal diseases. Orphanet J Rare Dis. 2016;11:86.

\section{Publisher's Note}

Springer Nature remains neutral with regard to jurisdictional claims in published maps and institutional affiliations.

\footnotetext{
Ready to submit your research? Choose BMC and benefit from:

- fast, convenient online submission

- thorough peer review by experienced researchers in your field

- rapid publication on acceptance

- support for research data, including large and complex data types

- gold Open Access which fosters wider collaboration and increased citations

- maximum visibility for your research: over $100 \mathrm{M}$ website views per year

At BMC, research is always in progress.

Learn more biomedcentral.com/submissions
} 